\title{
Quiet-condition variations in the scale height at F2-layer peak at Jicamarca during solar minimum and maximum
}

\author{
C.-C. Lee ${ }^{1}$ and B. W. Reinisch ${ }^{2}$ \\ ${ }^{1}$ General Education Center, Ching-Yun University, Jhongli City, Taoyuan County, Taiwan \\ ${ }^{2}$ Center for Atmospheric Research, University of Massachusetts, Lowell, Massachusetts, USA
}

Received: 13 August 2007 - Revised: 16 November 2007 - Accepted: 4 December 2007 - Published: 2 January 2008

\begin{abstract}
This study is the first attempt to examine the quiet-condition variations in scale height $(\mathrm{Hm})$ near the F2layer peak in the equatorial ionosphere. The data periods of $\mathrm{Hm}$ derived from the Jicamarca ionograms are JanuaryDecember 1996 and April 1999-March 2000. The results show that the greatest and smallest Hm values are generally at 11:00-12:00 LT and 04:00-05:00 LT, respectively. Additionally, the sunrise peak occurs at 06:00 LT only during solar minimum. The post-sunset peaks in the equinoctial and summer months are more obvious during solar maximum. The $\mathrm{Hm}$ difference between solar minimum and maximum are significant from afternoon to midnight. On the other hand, the Hm values during 07:00-10:00 LT for solar minimum are close to those for solar maximum. Furthermore, the correlation of $\mathrm{Hm}$ with the critical frequency (foF2) of F2-layer is generally low. In contrast, the correlation between $\mathrm{Hm}$ and the peak height (hmF2) of F2-layer is high. For $\mathrm{Hm}$ and the thickness parameter (B0) of F2-layer, the correlation between these two parameters is almost perfect.
\end{abstract}

Keywords. Ionosphere (Equatorial ionosphere; Modeling and forecasting)

\section{Introduction}

The understanding of the electron density profile, which is the altitude distribution of electron density, is important for the ionospheric studies. In general, the electron density profile of the bottomside ionosphere is provided by the measurements of ground-based digisonde/ionosonde (e.g. Reinisch, 1996) or by incoherent scatter radar (ISR) (e.g. Liu et al, 2007). For the topside ionosphere, the profile can be obtained from the ISR, the space-born instruments (e.g. Stankov et al., 2006), or by analytic functions. In the past decades, many

Correspondence to: C.-C. Lee

(cclee@cyu.edu.tw) analytic functions, such as Chapman, exponential, parabolic, and sech-squared functions, have been applied to depict the ionospheric profile (e.g. Booker, 1977; Rawer et al., 1985; Rawer, 1988; Di Giovanni and Radicella, 1990; Huang and Reinisch, 2001; Stankov et al., 2003). In these analytic functions, in addition to the density and height of F2-layer peak, the scale height is an important parameter to describe the ionospheric profile.

In Huang and Reinisch (2001) and Reinisch and Huang (2001), a new technique was introduced to derive the scale height $(\mathrm{Hm})$ near the F2-layer peak from the shape of the bottomside profile. Then, Reinisch et al. (2004) showed that the $\mathrm{Hm}$ can help to improve the model of topside profile in International Reference Ionosphere (IRI) (Bilitza, 2001). Recently, the diurnal, seasonal, and solar activity variations of $\mathrm{Hm}$ at Wuhan $\left(30.6^{\circ} \mathrm{N}, 114.4^{\circ} \mathrm{E}\right)$ and the yearly variation of $\mathrm{Hm}$ of Wuhan and 12 other stations were investigated by Liu et al. (2006). The diurnal and seasonal variations of $\mathrm{Hm}$ at Hainan $\left(19.4^{\circ} \mathrm{N}, 109.0^{\circ} \mathrm{E}\right)$ and two European stations were studied by Zhang et al. (2006) and Mosert et al. (2007), respectively. The Hm values were compared with the topside scale height of topside sounders model by Belehaki et al. (2006). Till now, the Hm near the dip equator has not been examined, although many studies of $\mathrm{Hm}$ have been done.

In the present work, the $\mathrm{Hm}$ values obtained from the equatorial ionograms recorded by the Jicamarca digisonde $\left(12^{\circ} \mathrm{S}, 76.9^{\circ} \mathrm{W}\right.$, dip latitude: $\left.1.0^{\circ} \mathrm{N}\right)$ during geomagnetic quiet-conditions are examined. The correlations of $\mathrm{Hm}$ with the critical frequency (foF2), peak height (hmF2), and thickness parameter (B0) of F2-layer are also analyzed here.

\section{Data analysis}

The ionograms used in this study were observed by the Jicamarca digisonde $\left(12^{\circ} \mathrm{S}, 76.9^{\circ} \mathrm{W}\right.$, dip latitude: $\left.1.0^{\circ} \mathrm{N}\right)$, near the dip equator. The data periods are January-December

Published by Copernicus Publications on behalf of the European Geosciences Union. 
Table 1. The monthly smoothed sunspot numbers (SSN) for January-December 1996 and April 1999-March 2000.

\begin{tabular}{lclc}
\hline $\begin{array}{l}\text { Month } \\
\text { (solar minimum) }\end{array}$ & $\begin{array}{c}\text { Monthly } \\
\text { SSN }\end{array}$ & $\begin{array}{l}\text { Month } \\
\text { (solar maximum) }\end{array}$ & $\begin{array}{c}\text { Monthly } \\
\text { SSN }\end{array}$ \\
\hline January 1996 & 10.4 & January 2000 & 112.9 \\
February 1996 & 10.1 & February 2000 & 116.8 \\
March 1996 & 9.7 & March 2000 & 119.9 \\
April 1996 & 8.4 & April 1999 & 85.5 \\
May 1996 & 8.0 & May 1999 & 90.5 \\
June 1996 & 8.5 & June 1999 & 93.1 \\
July 1996 & 8.4 & July 1999 & 94.3 \\
August 1996 & 8.3 & August 1999 & 97.5 \\
September 1996 & 8.4 & September 1999 & 102.3 \\
October 1996 & 8.8 & October 1999 & 107.8 \\
November 1996 & 9.8 & November 1999 & 111.0 \\
December 1996 & 10.4 & December 1999 & 111.1 \\
\hline
\end{tabular}

1996 and April 1999-March 2000. It is noted the solar cycle 23 started in May 1996 with the monthly smoothed sunspot number (SSN) at 8.0 and peaked in April 2000 at 120.8. The SSN of these 24 months are displayed in Table 1. Therefore, the period of January-December 1996 is categorized to the solar minimum; while the April 1999-March 2000 is attributed to the solar maximum.

The Jicamarca ionograms were downloaded from the Digital Ionogram DataBase (DIDBase). foF2 is obtained from the ionograms using the SAO-Explorer software package (http://ulcar.uml.edu/digisonde.html). The values of $\mathrm{hmF} 2, \mathrm{~B} 0$, and $\mathrm{Hm}$ were derived using the true height inversion algorithm NHPC (ftp://umlcar.uml. edu/SoftwareUtilities/NHPC/) (Reinisch and Huang, 1998; Huang and Reinisch, 2001) imbedded in the SAO-Explorer. In order to eliminate possible effects of geomagnetic disturbed-condition, the data of those days for geomagnetic quiet-conditions are applied in the following analyses. Notice that the geomagnetic quiet-condition means the sum of the eight $K p$ indices for the day is less than or equal to 24 $(\Sigma K p \leq 24)$.

\section{Results and discussion}

\subsection{Diurnal and seasonal variations of $\mathrm{Hm}$}

Figure 1 illustrates the monthly median values of $\mathrm{Hm}$ for the equinoctial (March-April and September-October 1996), summer (May, June, July, and August 1996), and winter (January-February and November-December 1996) months during solar minimum. In the equinoctial months (Fig. 1a), the $\mathrm{Hm}$ values exhibit a clear diurnal variation. The greatest and smallest values occur at 05:00 and 12:00 LT, respectively. This diurnal variation is understandable from the clas-
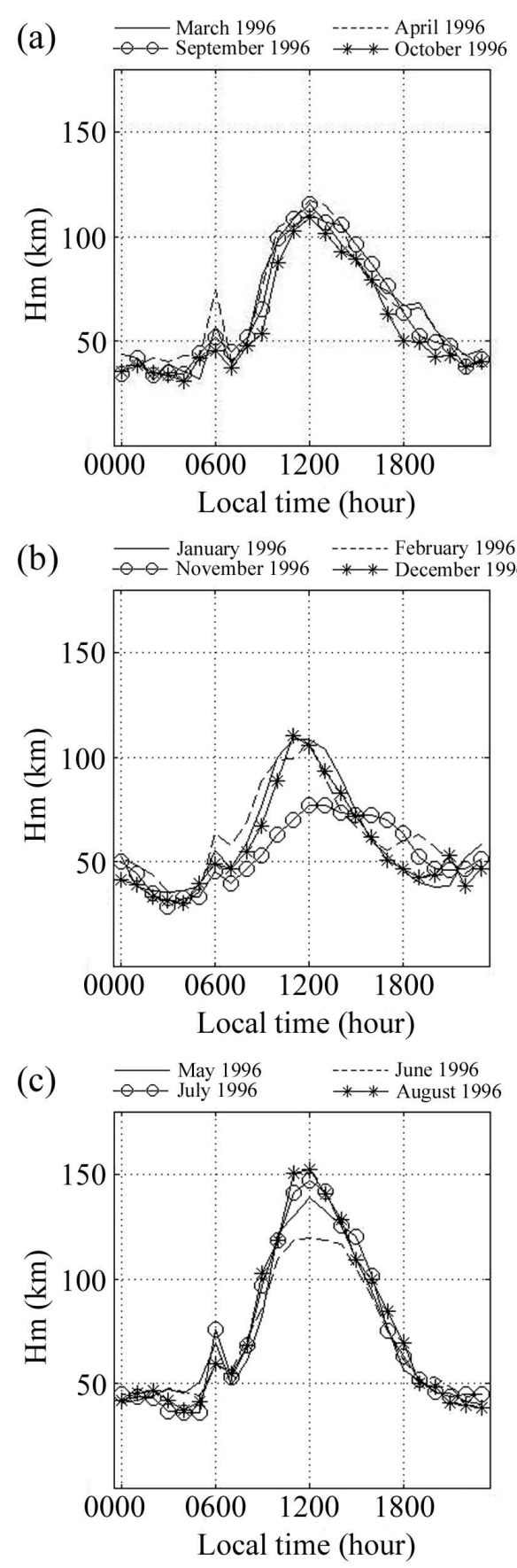

Fig. 1. The quiet-condition monthly median values of $\mathrm{Hm}$ for the (a) equinoctial, (b) summer, and (c) winter months during JanuaryDecember 1996.

sical definition of the neutral scale height $(\mathrm{Hm}=\mathrm{kT} / \mathrm{mg})$, in which the scale height is positively correlated to the temperature. Besides, two other smaller peaks are found in Fig. 1a. One peak is at 06:00 LT for all months; while another one is at 19:00 LT for March and April. According to the previous studies (Lee and Reinisch, 2006; Lee et al., 2007), these 


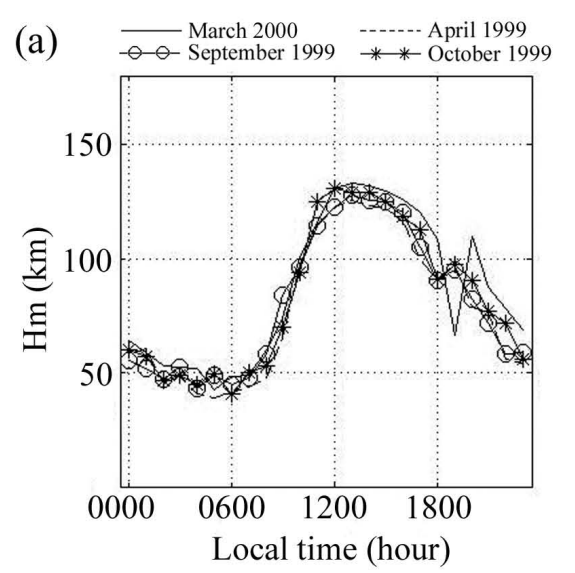

(b) $-\ominus-$ January $2000 \quad$ November $1999 \quad *$ * December 1999

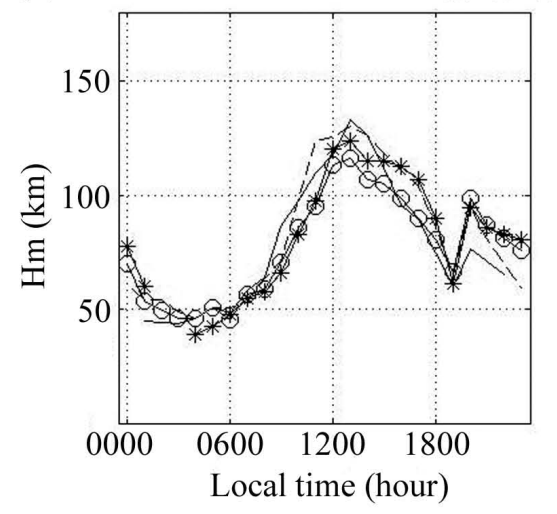

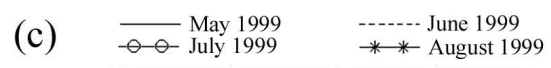

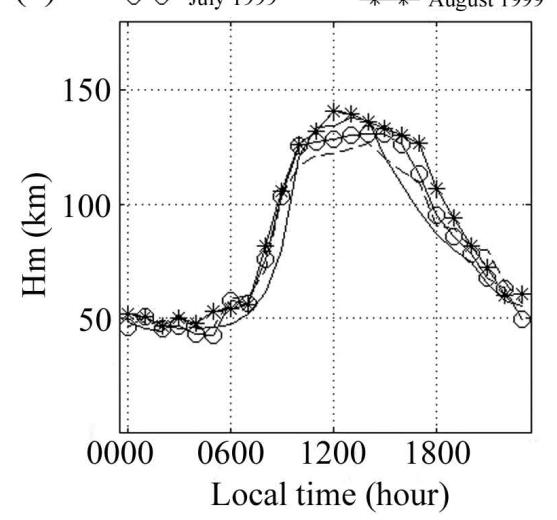

Fig. 2. The quiet-condition monthly median values of $\mathrm{Hm}$ for the (a) equinoctial, (b) summer, and (c) winter months during April 1999-March 2000.

two peaks might not be produced by an increasing temperature, but by the shape change of the electron density profile. In the sunrise period, the shape change of electron profile due to the solar production at higher altitudes would form an increase of hmF2 and B0 (Lee et al., 2007). Further, this kind of change could cause a sunrise peak of Hm. During the post-sunset period, the pre-reversal enhancement (PRE)

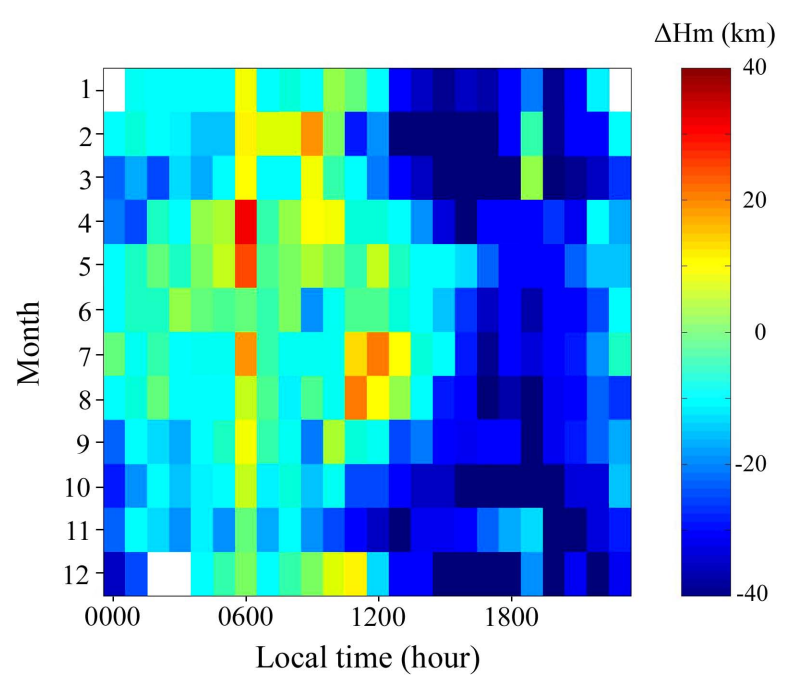

Fig. 3. The difference $(\Delta \mathrm{Hm})$ of monthly median $\mathrm{Hm}$ between solar minimum and maximum. Notice that the $\Delta \mathrm{Hm}$ is obtained by subtracting the monthly median $\mathrm{Hm}$ for solar maximum from that for solar minimum.

of $\boldsymbol{E} \times \boldsymbol{B}$ drift velocity (Farley et al., 1986) would make the post-sunset peaks of hmF2 and B0 (Lee and Reinisch, 2006; Lee et al., 2007), and in turn form a post-sunset peak in $\mathrm{Hm}$.

In Fig. 1b, the diurnal variations of $\mathrm{Hm}$ in the summer months are similar to those in the equinoctial months, except November. For January, February, and December, the greatest and smallest values of $\mathrm{Hm}$ are at 04:00-05:00 LT and 11:00-12:00 LT, respectively. For November, the daytime variation of $\mathrm{Hm}$ is different from those observed in the three other months. Based on the results for $\mathrm{hmF} 2$ and $\mathrm{B} 0$ in November 1996 (Lee et al., 2007), this different daytime variation in $\mathrm{Hm}$ is caused by the variation in the vertical velocity. Furthermore, in this season, the post-sunset peak occurs at different time for each month. These different occurring times of post-sunset peaks are related to the different behaviors of the PRE $\boldsymbol{E} \times \boldsymbol{B}$ drift velocity, which also produce the different times of the $\mathrm{hmF} 2$ and $\mathrm{B} 0$ peaks in the post-sunset period (Lee et al., 2007).

In the winter months (Fig. 1c), the diurnal variations are generally similar to those observed in two other seasons. It is noted that the maximum $\mathrm{Hm}$ values at 12:00 LT in this season are larger than those observed in the equinoctial and summer months. In winter, the B0 values are larger than those observed in other seasons (Lee et al., 2007). Therefore, the larger $\mathrm{Hm}$ values would be related to the larger $\mathrm{B} 0$ values in this season, because $\mathrm{Hm}$ is highly correlated to B0 (see Sect. 3.2). Moreover, the post-sunset peak does not appear, because the PRE $\boldsymbol{E} \times \boldsymbol{B}$ drift velocity is not obvious in this season (Fejer et al., 1999; Lee et al., 2007).

For solar maximum, the monthly median values of $\mathrm{Hm}$ for the equinoctial (March 2000, and April, September 

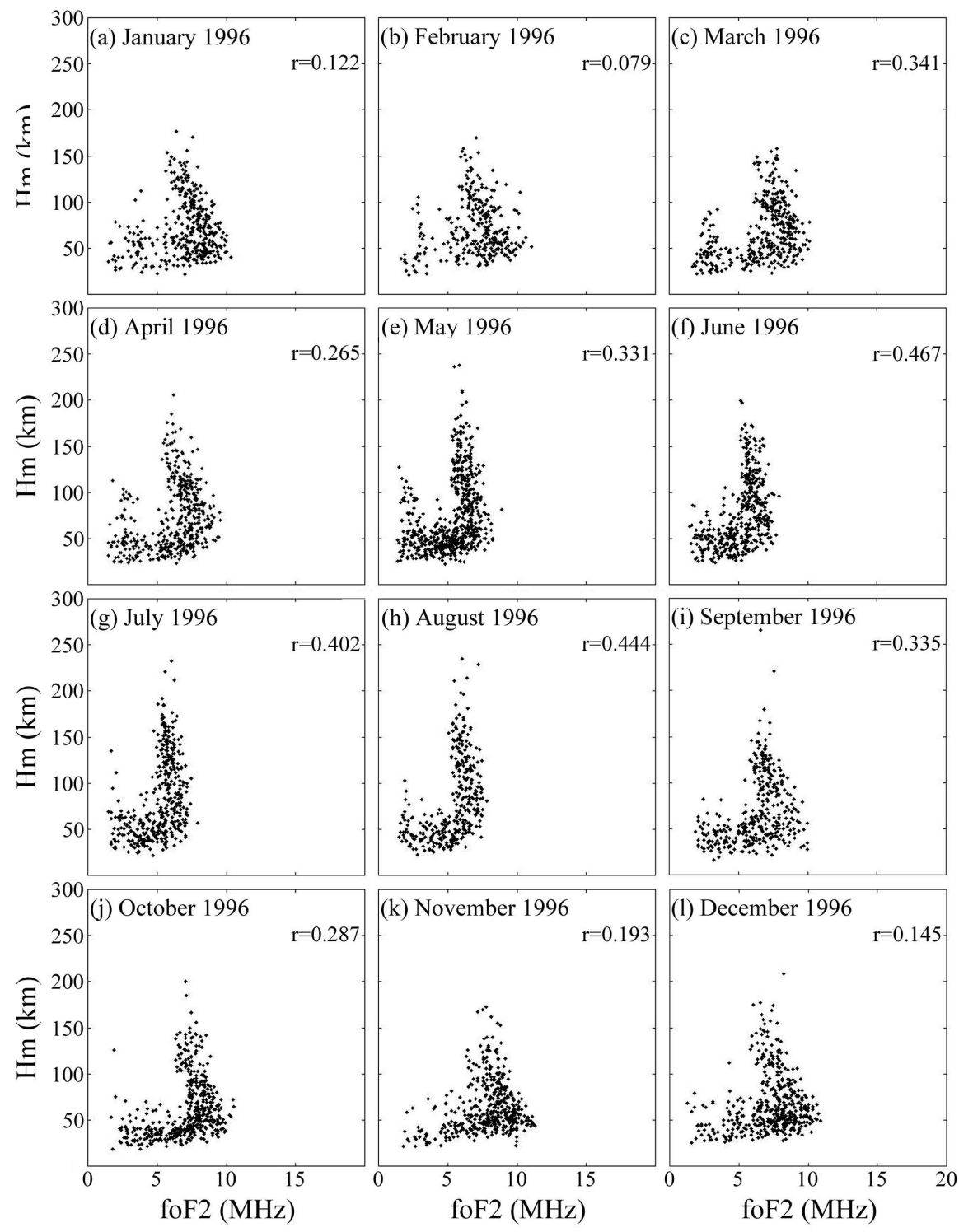

Fig. 4. The scatter plots of Hm versus foF2 during January-December 1996. The correlation coefficient $(r)$ of $\mathrm{Hm}$ and foF2 is placed in the upper-right corner.

and October 1999), summer (May, June, July, and August, 1999), and winter (January-February 2000 and NovemberDecember 1999) months are displayed in Fig. 2. In Fig. 2a, the occurring times for the greatest (12:00-13:00 LT) and smallest (05:00-06:00 LT) values are generally close to those for solar minimum. However, two significant differences are found between solar minimum and maximum. One is that the sunrise Hm peak does not exist during solar maximum. This absent sunrise peak indicates that the effect of solar production at higher altitudes on the profile change does not appear during solar maximum. The other difference is that the $\mathrm{Hm}$ values have a larger post-sunset peak during solar maximum. According to Fejer et al. (1999), this larger post- sunset peak is because of the larger PRE drift velocity during solar maximum. In Fig. $2 b$, the diurnal variations in the summer months are close to those in the equinoctial months, except the later post-sunset peaks. The later post-sunset peak is formed by the later reversal time of PRE drift velocity (Fejer et al., 1999). In the winter months (Fig. 2c), the diurnal variations are similar to those in two other seasons, but the peaks do not appear during the sunset period. It is noted during April 1999-March 2000, that the maximum Hm values at noon are slightly smaller in the summer months, because the maximum B0 values at noon are smaller in the summer months (Lee and Reinisch, 2006). 

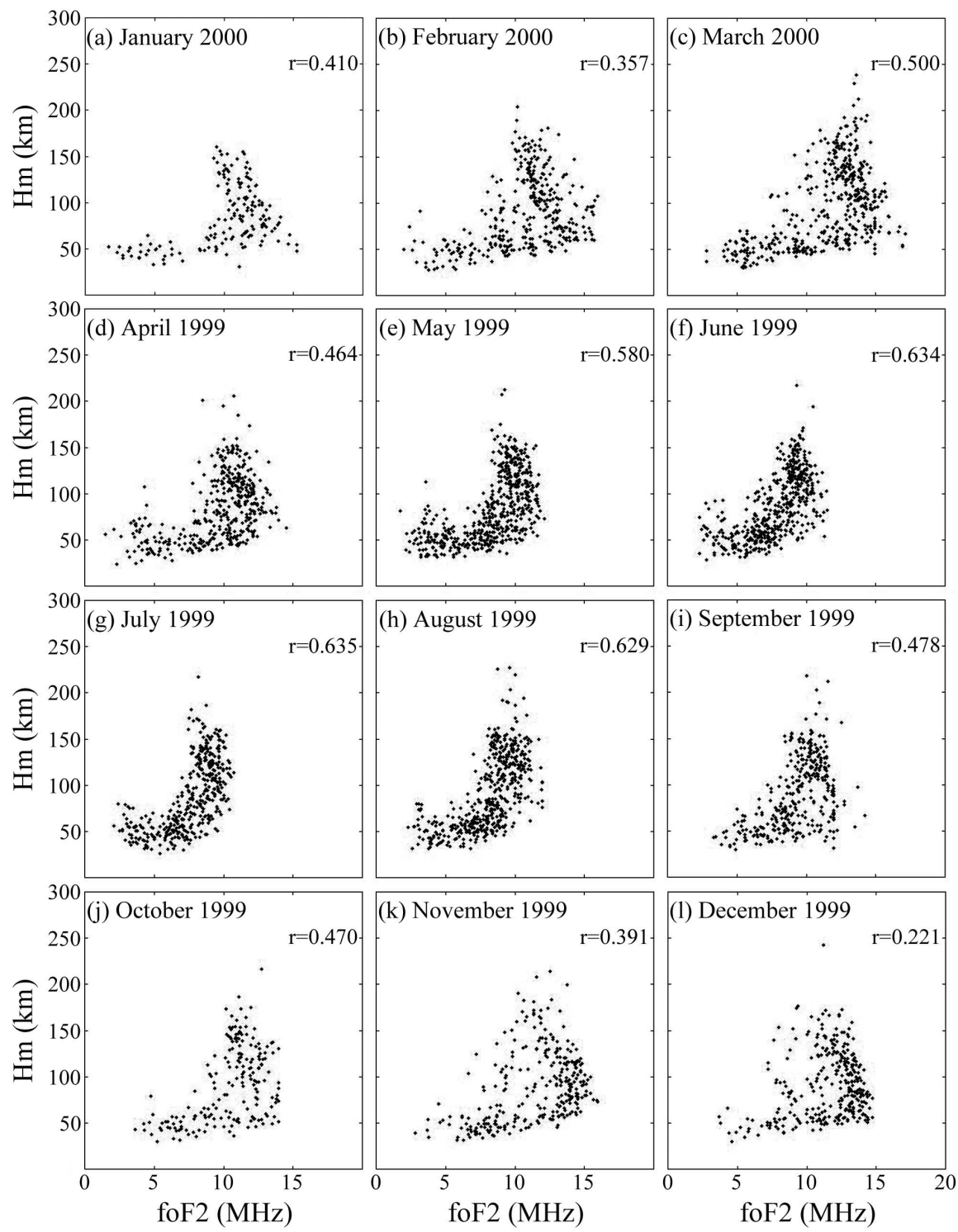

Fig. 5. The scatter plots of Hm versus foF2 during April 1999-March 2000. The correlation coefficient $(r)$ of Hm and foF2 is placed in the upper-right corner.

Figure 3 shows the $\Delta \mathrm{Hm}$ values where $\Delta \mathrm{Hm}$ is the difference of the monthly median values of $\mathrm{Hm}$ during solar minimum and the corresponding median values during solar maximum. The significantly negative $\Delta \mathrm{Hm}$ from afternoon to midnight demonstrate that the $\mathrm{Hm}$ for solar maximum is obviously larger than that observed for solar minimum during this time period. Furthermore, the positive differences at noon in the winter months indicate that the noontime $\mathrm{Hm}$ for this season is larger during solar minimum. In contrast, the negative differences at noon in the equinoctial and summer months reveal that the noontime $\mathrm{Hm}$ is smaller for these two seasons during solar minimum. In addition, the $\mathrm{Hm}$ values during 07:00-10:00 LT of solar minimum and maximum are close. This similarity indicates that the $\mathrm{Hm}$ values during 07:00-10:00 LT are not varied by the solar activity.

\subsection{Correlations of $\mathrm{Hm}$ with foF2, hmF2, and B0}

Figures 4 and 5 show the scatter plots of $\mathrm{Hm}$ versus foF 2 for solar minimum (January to December 1996) and solar maximum (April 1999 to March 2000), respectively. The correlation coefficients $(r)$ of $\mathrm{Hm}$ and foF2 are also displayed in the figures. The analysis of the coefficients shows that during solar minimum (Fig. 4) the correlation between $\mathrm{Hm}$ and foF2 is poor in summer $(r=0.079-0.193)$, low in equinox $(r=0.265-$ $0.341)$, and moderate in winter $(r=0.402-0.467)$. For solar 

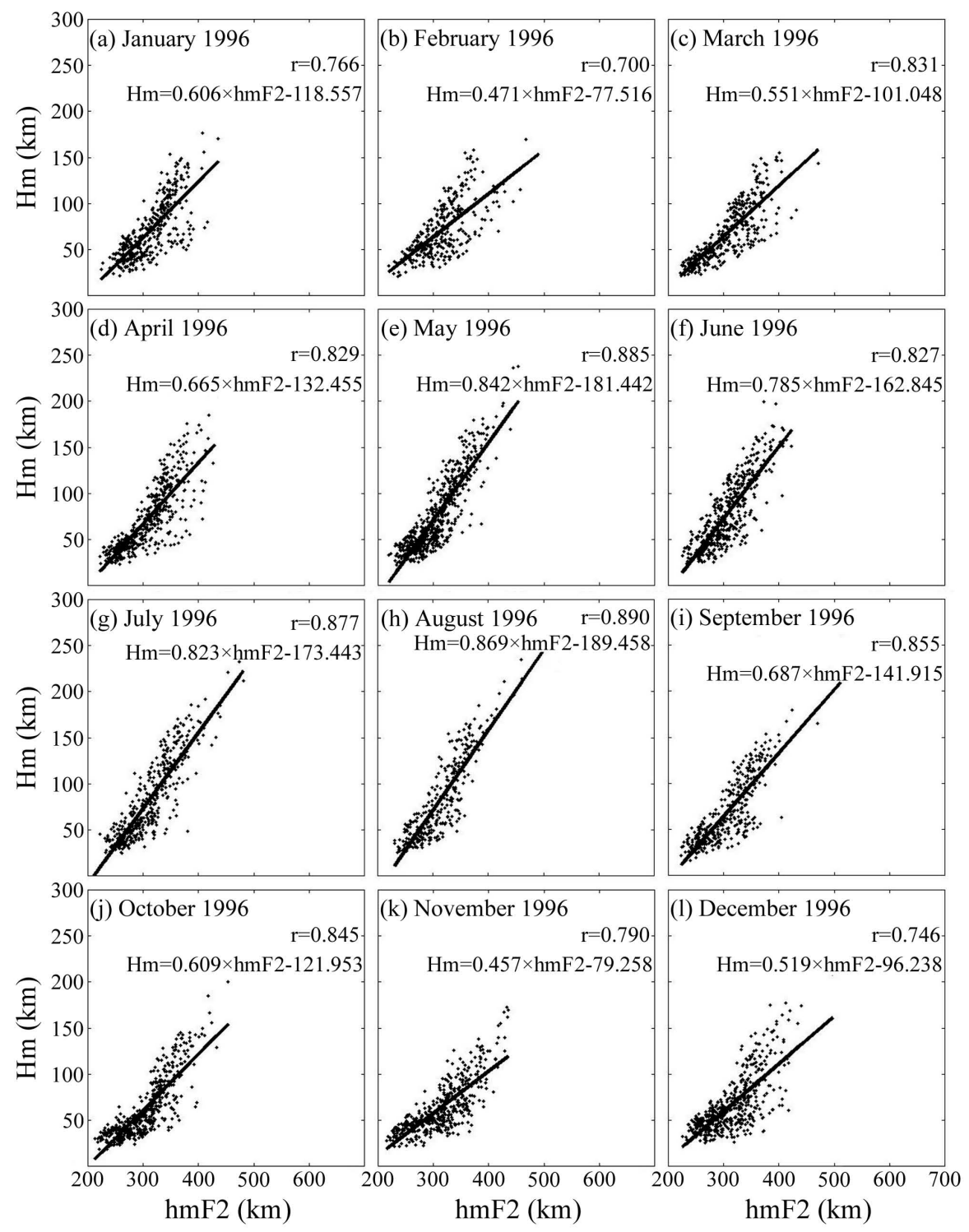

Fig. 6. The scatter plots of Hm versus hmF2 during January-December 1996. The correlation coefficient $(r)$ of Hm and hmF2 and the equation of least-squares straight line (solid line) for each month are placed in the upper-right corner.

maximum (Fig. 5), the correlation between $\mathrm{Hm}$ and foF2 is better than during solar minimum. The correlation coefficients range between 0.221 and 0.410 in summer, between 0.464 and 0.50 in equinox, and between 0.580 and 0.635 in winter. These results near the dip equator are not the totally same as those observed at other latitudes. At low-latitude, Liu et al. (2006) showed that a weak negative or poor correlation exists between $\mathrm{Hm}$ and foF2 at Wuhan $\left(30.6^{\circ} \mathrm{N}\right.$, $\left.114.4^{\circ} \mathrm{E}\right)$. The poor correlation was also found Zhang et al. (2006) using data from the low-latitude station, Hainan $\left(19.4^{\circ} \mathrm{N}, 109.0^{\circ} \mathrm{E}\right)$. The larger $r$ values at Jicamarca demonstrate that the correlation between $\mathrm{Hm}$ and foF 2 in the equatorial ionosphere is higher than those at other latitudes.
In Fig. 6, the scatter plots of $\mathrm{Hm}$ versus $\mathrm{hmF} 2$, and the associated correlation coefficients and least-squares straight lines for January-December, 1996 are presented. In Fig. 6c-j, the $\mathrm{Hm}$ and $\mathrm{hmF} 2$ have a high correlation $(r=0.827-0.890)$ in the equinoctial and winter months (Fig. $6 \mathrm{c}-\mathrm{j}$ ). For the summer months (Fig. 6a-b and k-1), Hm are markedly correlated to hmF2 $(r=0.700-0.790)$. These $r$ values for solar minimum are close to those for solar maximum (Fig. 7). For solar maximum, the Hm is highly correlated to hmF2 $(r=0.802-0.833)$, except January 2000 ( $r=0.773)$. Overall, the $r$ values between $\mathrm{Hm}$ and $\mathrm{hmF} 2$ are larger in the equinoctial and winter months than in the summer months. It is noted that the greatest $r$ values exists in August for both solar minimum and 

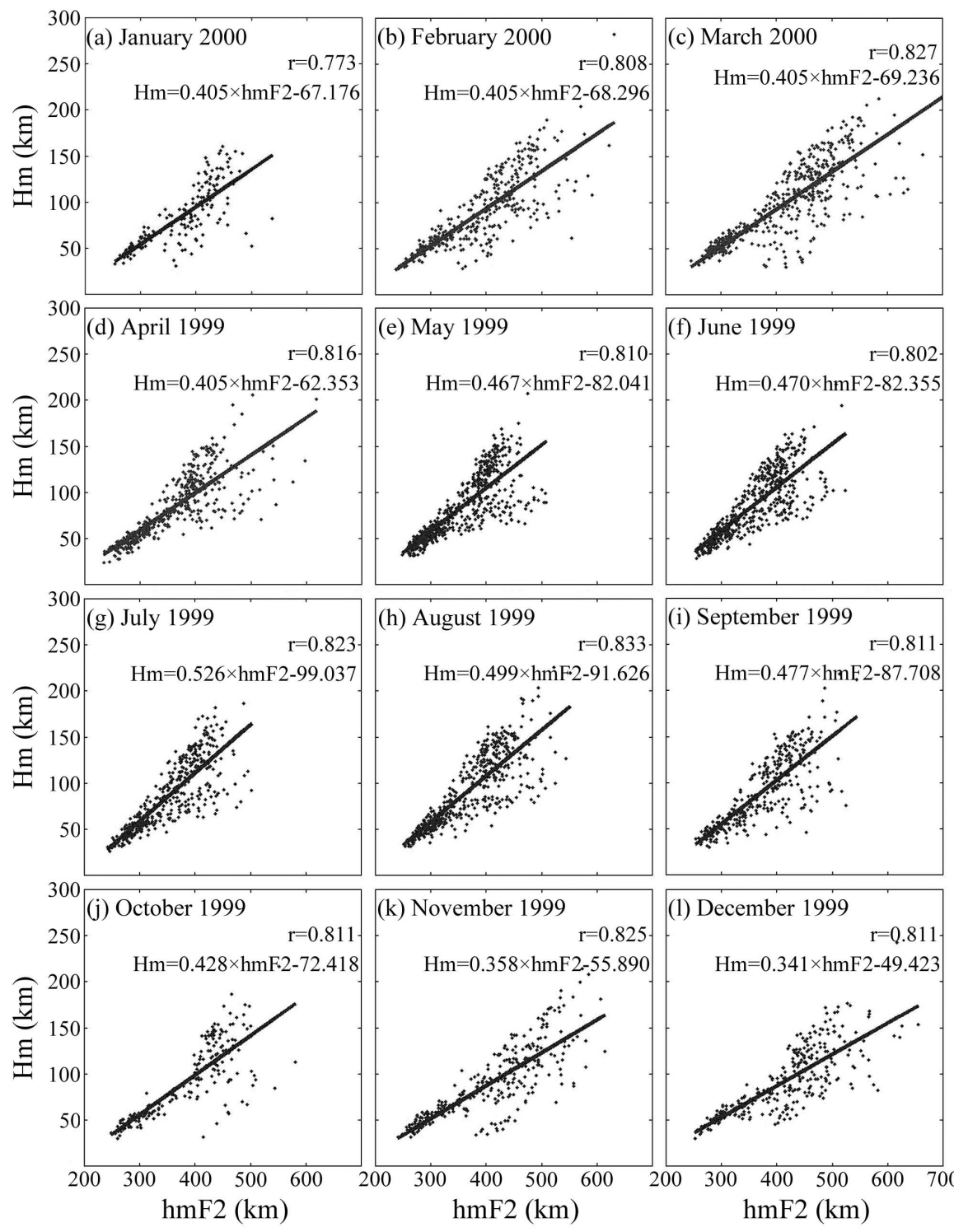

$\mathrm{Hm}=0.341 \times \mathrm{hmF} 2-49.423$

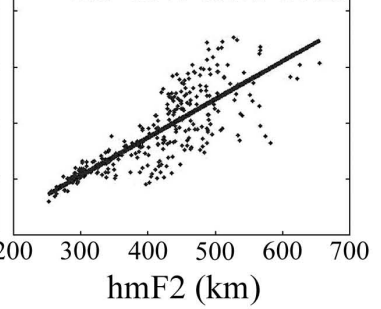

Fig. 7. The scatter plots of Hm versus hmF2 during April 1999-March 2000. The correlation coefficient $(r)$ of Hm and hmF2 and the equation of least-squares straight line (solid line) for each month are placed in the upper-right corner.

maximum. In August 1996 (Fig. 6h), the $r$ value is 0.890 and the straight line is given as $\mathrm{Hm}=0.869 \times \mathrm{hmF} 2-189.458$. In August 1999 (Fig. 7h), the $r$ value is 0.833 and the straight line is given as $\mathrm{Hm}=0.499 \times \mathrm{hmF} 2-91.626$. In addition, the $r$ values of the equinoctial and winter months are larger during solar minimum than during solar maximum. On the other hand, the $r$ values of the summer months are smaller during solar minimum than during solar maximum.

The high correlation between $\mathrm{Hm}$ and $\mathrm{hmF} 2(r=0.700$ 0.890) demonstrate that the physical processes controlling the $\mathrm{hmF} 2$ variations might also be responsible for the $\mathrm{Hm}$ variations. In the equatorial ionosphere, the $\mathrm{hmF} 2$ variation mainly depends on the vertical $\boldsymbol{E} \times \boldsymbol{B}$ velocity because of the horizontal geomagnetic field line (Lee and Reinisch, 2006; Lee et al., 2007). Therefore, the Hm variation near the dip equator would be also affected by the vertical $\boldsymbol{E} \times \boldsymbol{B}$ velocity. Moreover, the $r$ values in this study are larger than those in Liu et al. (2006) and Zhang et al. (2006). This suggests that dependence of $\mathrm{Hm}$ on $\mathrm{hmF} 2$ is more obvious near the dip equator than at low-latitudes.

Figures 8 and 9 illustrate the scatter plots of Hm versus B0, and the associated correlation coefficients and least-squares straight lines for solar minimum and maximum, respectively. The $r$ values (0.959-0.977) for all 24 months reveal that $\mathrm{Hm}$ has an almost perfect correlation with B0 for both solar minimum and maximum. Values of $r$ larger than 0.90 are also 

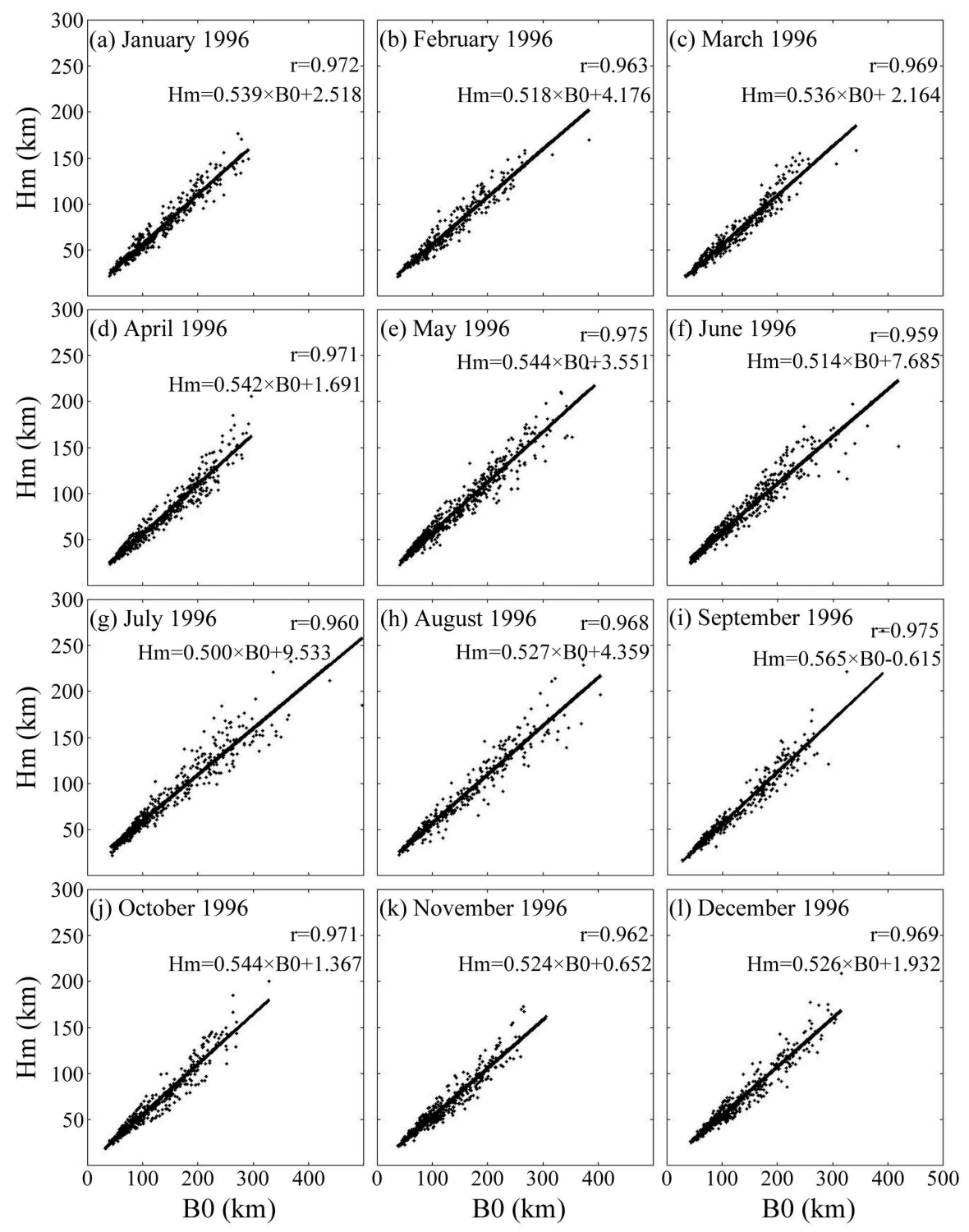

Fig. 8. The scatter plots of Hm versus B0 during January-December 1996. The correlation coefficient $(r)$ of $\mathrm{Hm}$ and B0 and the equation of least-squares straight line (solid line) for each month are placed in the upper-right corner.

found at low-latitudes (Liu et al., 2006; Zhang et al., 2006). These results indicate that the $\mathrm{Hm}$ values in the equatorial ionosphere can be estimated from the B0 values, based on the equations of least-squares straight lines in Figs. 8 and 9. For the ionospheric model, especially for IRI-2001 (Bilitza, 2001), the electron profile of topside ionosphere can be derived from the $\mathrm{B} 0$ parameter.

\section{Summary}

In this study, we analyze for the first time, the diurnal and seasonal variations of the scale height $(\mathrm{Hm})$ at $\mathrm{F}$ 2-layer peak near the dip equator during the solar minimum and maximum. The Hm values are derived from the Jicamarca ionograms from January to December 1996 and from April 1999 to March 2000. To eliminate the effects of geomagnetic disturbances, only the data under quiet-conditions are used in the study. The correlations of $\mathrm{Hm}$ with foF2, hmF2 and $\mathrm{B} 0$ are also calculated.

The diurnal variations of $\mathrm{Hm}$ generally have the greatest value at 11:00-12:00 LT and the smallest one at 04:0005:00 LT for both solar minimum and maximum. Furthermore, the sunrise peak at 06:00 LT is only found during solar minimum. The post-sunset peaks in the equinoctial and summer months are clearer during solar maximum. In the winter 

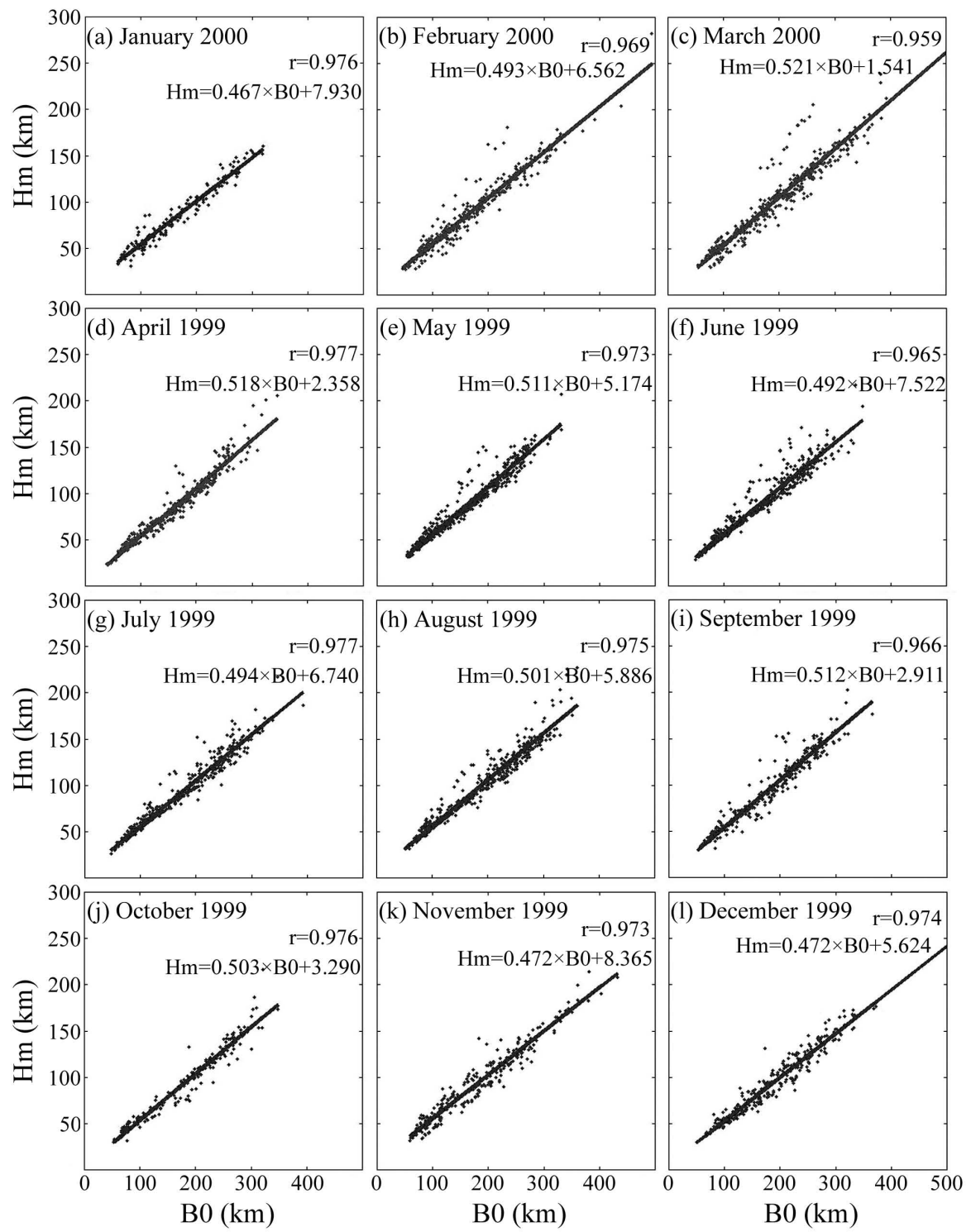

Fig. 9. The scatter plots of Hm versus B0 during April 1999-March 2000. The correlation coefficient $(r)$ of Hm and B0 and the equation of least-squares straight line (solid line) for each month are placed in the upper-right corner.

months, the post-sunset peak is absent for both solar minimum and maximum. During solar minimum, the maximum $\mathrm{Hm}$ values at noon are greater in the winter months. During solar maximum, the maximum $\mathrm{Hm}$ values at noon are greater in the equinoctial and winter months. The Hm differences are significant from afternoon to midnight. In contrast, the $\mathrm{Hm}$ values of solar minimum and maximum are close to each other during 07:00-10:00 LT.

The correlation coefficients between $\mathrm{Hm}$ and foF 2 are less than 0.40 during 9 months of the low solar activity year and during 3 months of the high solar activity period. The moderate correlations $(r=0.402-0.580)$ appear in 3 months of solar minimum and 6 months of solar maximum. Only 3 months
(June-August 1999) have a marked degree of correlation $(r=0.629-0.634)$ of $\mathrm{Hm}$ and foF 2 . These results indicate that the $\mathrm{Hm}$ is generally poorly correlated to foF 2 . In contrast, the correlation between $\mathrm{Hm}$ and $\mathrm{hmF} 2$ is high $(r=0.700-0.890)$. These $r$ values suggest that the vertical drift velocity, which is the major physical processes controlling $\mathrm{hmF} 2$ in the equatorial ionosphere, would affect the Hm variations. The high degree of correlation between $\mathrm{Hm}$ and B0 ( $r=0.959-0.977)$ during low and high solar activity indicates that the B0 parameter (observed or modelled) can be used to estimate the $\mathrm{Hm}$ values in order to describe the topside electron density profile. 
Acknowledgements. CCL was supported by the grant of National Science Council NSC 96-2119-M-231-001. BWR was supported by the AF grant \#FA8718-06-C-0072. The authors would like to thank UML for access to DIDBase (http://ulcar.uml.edu/DIDBase/), and to the National Geophysical Data Center (NGDC) (http://www. ngdc.noaa.gov/) for providing data of $K p$ and sunspot number. The authors thank the two referees for the valuable comments and suggestions.

Topical Editor M. Pinnock thanks two anonymous referees for their help in evaluating this paper.

\section{References}

Belehaki, A., Marinov, P., Kutiev, I., Jakowski, N., and Stankov, S.: Comparison of the topside ionosphere scale height determined by topside sounders model and bottomside digisonde profile, Adv. Space Res., 37, 963-966, 2006.

Bilitza, D.: International Reference ionosphere 2000, Radio Sci., 36, 261-275, 2001.

Booker, H. G.: Fitting of multi-region ionospheric profiles of electron density by a single analytic function of height, J. Atmos. Terr. Phys., 39, 619-623, 1977.

Di Giovanni, G. and Radicella, S. M.: An analytical model of the electron density profile in the ionosphere, Adv. Space Res., 10(11), 27-30, 1990.

Farley, D. T., Bonelli, E., and Fejer, B. G..: The pre-reversal enhancement of the zonal electric field in the equatorial ionosphere. J. Geophys. Res., 91, 13 723-13 728, 1986.

Fejer, B. G., de Paula, E. R., Gonzales, S. A., and Woodman, R. F.: Average vertical and zonal plasma drift over Jicamarca, J. Geophys. Res., 96, 13 901-13 906, 1991.

Fejer, B. G., Scherliess, L., and de Paula, E. R.: Effects of the vertical plasma drift velocity on the generation and evolution of equatorial F, J. Geophys. Res., 104, 19 859-19869, 1999.

Huang, X. and Reinisch, B. W.: Vertical electron content from ionogram in real time, Radio Sci., 36, 335-342, 2001.

Lee, C. C. and Reinisch, B. W.: Quiet-condition hmF2, NmF2, and B0 variations at Jicamarca and comparison with IRI-2001 during solar maximum, J. Atmos. Sol.-Terr. Phy., 68, 18, 2138-2146, 2006.

Lee, C. C., Reinisch, B. W., Su, S. -Y., and Chen, W. S.: Quiet-time variations of F2 layer parameters at Jicamarca and comparison with IRI-2001 during solar minimum, J. Atmos. Sol-Terr. Phy., in press, 2007.
Liu, L., Wan, W., and Ning, B.: A study of the ionogram derived effective scale height around the ionospheric hmF2, Ann. Geophys., 24, 851-860, 2006, http://www.ann-geophys.net/24/851/2006/.

Liu, L., Le, H., Wan, W., Sulzer, M. P., Lei, J. and Zhang, M. L.: An analysis of the scale height in the lower topside ionosphere based on the Arecibo incoherent scatter radar measurements, J. Geophys. Res., 112, A06307, doi:10.1029/2007JA012250, 2007.

Mosert, M., Ezquer, R., de la Morene, B., Altadill, D., Mansilla, G., and Miro Amarante, G.: Behaviors of the scale height at the Fe layer peak derived from digisonde measurements at tow $\mathrm{Eu}-$ ropean stations, Adv. Space Res., 39, 755-758, 2007.

Rawer, K.: Synthesis of ionospheric electron density profiles with Epstein functions, Adv. Space Res., 8(4), 191-198, 1988.

Rawer, K., Bilitza, D., and Gulyaeva, T. L.: New formulas for IRI electron density profile in the topside and middle ionosphere, Adv. Space Res., 5(7), 3-12, 1985.

Reinisch, B. W.: Modern ionosondes, in Modern Radio Science, edited by: Kohl, H., Ruester, R., and Schlegel, K., European Geophysical Society, Katlenburg-Lindau, Germany, 440-458, 1996.

Reinisch, B. W. and Huang, X.: Finding better B0 and B1 parameters for the IRI F2 profile function, Adv. Space Res., 22, 741747, 1998

Reinisch, B. W. and Huang, X.: Deducing topside profile and total electron content form bottomside ionograms, Adv. Space Res., 27(1), 23-30, 2001.

Reinisch, B. W., Huang, X. Q., Belehaki, A., Shi, J. H., Zhang, M. L., and Iima, R.: Modeling the IRI topside profile using scale heights from ground-based ionosonde measurements, Adv. Space Res., 34(9), 2026-2031, 2004.

Stankov, S. M. and Jakowski, N.: Topside plasma scale height retrieved from radio occultation measurements, Adv. Space Res., 37, 958-962, 2006.

Stankov, S. M., Jakowski, N., Heise, S., Muhtarov, P., Kutiev, I., and Warnant, R.: A new method for reconstruction of the vertical electron density distribution in the upper ionosphere and plasmasphere, J. Geophys. Res., 108(A5), 1164, doi:10.1029/2002JA009570, 2003.

Zhang, M. L., Reinisch, B. W., Shi, J. K., Wu, S. Z., and Wang, $\mathrm{X}$.: Diurnal and seasonal variation of the ionogram-derived scale height at the F2 peak, Adv. Space Res., 37, 967-971, 2006. 